\title{
Firearm Injuries at Selected Hospitals in Kenya
}

\begin{abstract}
Njeru E.K., BSc, MSc, Mutiso V.M., MBChB, MMed, FCS (ESA), Saidi H., BSc, MBChB, MMed, FCS (ECSA), FACS, School of Medicine, University of Nairobi, Nairobi, Kenya, Mak'Anyengo K., MBChB, MMed, Gakuru J.N., MD, FAAD, Department of Defence, Nairobi, Kenya

Corresponding author: E.K. Njeru, Department of Community Health/Clinical Epidemiology Unit, School of Medicine, University of Nairobi, Nairobi, Kenya, Email: njeruerastusk@yahoo.co.uk
\end{abstract}

\section{Abstract}

BACKGROUND: The burden of injury in low-income countries is greater than in highincome countries, but injury documentation and prevention policies are inadequate. The who, where and how of firearm injuries in Kenya has received little attention.

OBJECTIVE: This study describes the epidemiology of small and light firearm injuries to highlight the problem and stimulate further methodologically and scientifically sound research in the area.

METHOD: This retrospective study involved abstracting socio-demographic data, injury mechanism, intention, resources consumed and outcome information from case notes in the records departments of two major health facilities in Nairobi.

RESULTS: Eight hundred and fifty two hospital admissions due to gun-shot injuries were recorded between 1997 - 2002 (average, 142 per year) representing $1.8 \%$ of all injury admissions, and $0.2 \%$ of total admissions at the two hospitals. There were 10 times more male admissions and $89.9 \%$ of those involved were in the 15-44 year age group. Six hundred and twenty nine $(85.9 \%)$ of the admissions were as a result of intentional injuries (assaults) while 101 $(13.8 \%)$ were as a result of unintentional injuries. Fourty two $(5 \%)$ patients died in hospital while $800(94.5 \%)$ were discharged home. The burden on health care facilities included a total of 15,392 ward days for 841 patients whose records were available and a total of 144 ICU days for 19 patients. Seven hundred and eighty four $(92.9 \%)$ patients underwent some form of surgery, mostly limb surgical toilet with wound excision/debridement. Hospital resources used included 3346 units of intravenous fluids and 518 units of blood.

CONCLUSION: The study recommends that policy makers be sensitized on the magnitude of this problem and more studies on risk factors to be carried out so that the process of testing interventions can begin.

\section{Introduction}

Injury is increasingly recognized as a global public health concern. Low-income countries carry the greatest burden of injury. Unfortunately, it is here that trauma care systems are unavailable or deficient (1). Owing to relative poverty, the outcome of injuries is decidedly worse than similar severity of injuries in more developed countries of Europe and North America. These injury outcomes have marked effects on social, economic and ultimately the health of the population. Well-designed studies and valid information on the burden and pattern of injuries in Africa and the so-called Least Developed Countries of the world are urgently needed. Relevant and valid injury data in these data-poor nations are vital for generation of preventionoriented policies (2).

In Kenya, injuries are occurring with greater severity (3) and daily reports in both the popular print and visual media indicate an increasing trend in injuries due to violence. Firearms 
comprise an important component of this trend. Most Nairobi inhabitants know of somebody or have themselves been involved in an incident where arms have been used. The scene of injury is often the home or street in episodes of violent robberies or car-jacking.

This study provides a descriptive epidemiology of small arms injuries in Kenya using a sample of health facilities in Nairobi.

\section{Methodology}

This was an exploratory survey in which purposive sampling of facilities was carried out to provide a perception of the data that may be available in health facilities over the six year period 1997-2002. The facilities selected for this survey included Kenyatta National Hospital and Forces Memorial Hospital in Nairobi. Kenyatta National hospital is the largest hospital in the city and receives over $90 \%$ of Nairobi's trauma burden. The Forces Memorial Hospital receives members of the country's security forces and their families. A few private hospitals in the city receive a minority of injured patients. To provide an outlook of the situation in rural Kenya, two hospitals, Embu Provincial General Hospital in Eastern Province and Mukumu Mission Hospital in Western Province were also selected for the study.

The main variable for the study was the occurrence of a firearm injury or fatality. The intent of the injury was derived from the overall impression discernible from the case notes. The burden on the health care facility was estimated using variables measuring procedures done, materials used and duration of hospital stay.
Data were collected using pre-designed forms for abstraction of information from existing hospital records. These forms were adapted from Injury Prevention Initiative for Africa (IPIFA) trauma registries used to collect data elsewhere in Africa. For each of the participating health facilities, a medical records clerk was recruited and trained on the use of the forms. Quality of the data collected was assured by intensive and strict supervision of the recorders and the data entry clerks.

Ethical clearance was sought and obtained from Kenyatta National Hospital Scientific and Ethical Committee as well as the National Council for Science and Technology.

\section{Results}

Visits to the two hospitals in the rural areas revealed that the incidence of firearm injuries in the hospital records was very low (4 records in Embu and six records in Mukumu over the six year period 1997-2002), so data from the two rural hospitals was excluded from the analysis.

Secular trends: Between 1997 and 2002 there were 474,188 admissions due to all causes in the two hospitals, out of which 47,522 were due to injuries. Case notes from the admissions due to injuries indicated that $852(1.8 \%)$ were due to small arms (Table 1). Six hundred and fifty four $(79.4 \%)$ of the incidents which resulted into injury due to small arms took place in Nairobi, the capital city.

The proportion of admissions due to small arms injuries out of the total admissions in the two hospitals increased steadily from $0.09 \%$ in

Table 1: Admission trends

\begin{tabular}{lccccc}
\hline Year & Total admissions & All injuries & $\begin{array}{c}\text { Small arms } \\
\text { injuries }\end{array}$ & $\begin{array}{c}\text { Percent of all } \\
\text { injuries }\end{array}$ & $\begin{array}{c}\text { Percent of total } \\
\text { admissions }\end{array}$ \\
\hline 1997 & 61985 & 6255 & 55 & 0.879 & 0.089 \\
1998 & 69664 & 7328 & 86 & 1.174 & 0.123 \\
1999 & 94955 & 7857 & 186 & 2.367 & 0.196 \\
2000 & 84082 & 8526 & 125 & 1.466 & 0.149 \\
2001 & 83336 & 8358 & 205 & 2.453 & 0.246 \\
2002 & 80166 & 9198 & 192 & 2.087 & 0.240 \\
\hline Total & 474188 & 47522 & $849^{*}$ & 1.8 & 0.18 \\
\hline
\end{tabular}

* The year of admission was not recorded for three of the small arms injury patients. 
1997 to $0.24 \%$ in 2002 , although with a slight reduction in the year 2000 (Figure 1).

Figure 2 also indicates a similar trend in the increase in the proportion of small arms injuries in relation to the total number of injuries from all causes ( $0.9 \%$ in 1997 to $2.1 \%$ in 2002), again with a decrease in the year 2000 .

Demographic profile: Eight hundred and fifty two patients (752 males, 76 females and 24 for whom sex was not recorded) were admitted to the two hospitals for firearm related injuries in the period under study, with a male: female ratio of 9.7:1. The male female ratio was highest (28.5:1) in patients 45 years and older. The age/ sex distribution of the patients involved is presented in Table 2.

Intent and Outcome: Six hundred and twenty nine $(85.9 \%)$ of the injuries recorded were intentional (assaults). Unintentional injuries accounted for 101 (13.8\%) of the patients while

\section{Figure 1: Proportion of small arms injuries out of the total admissions}

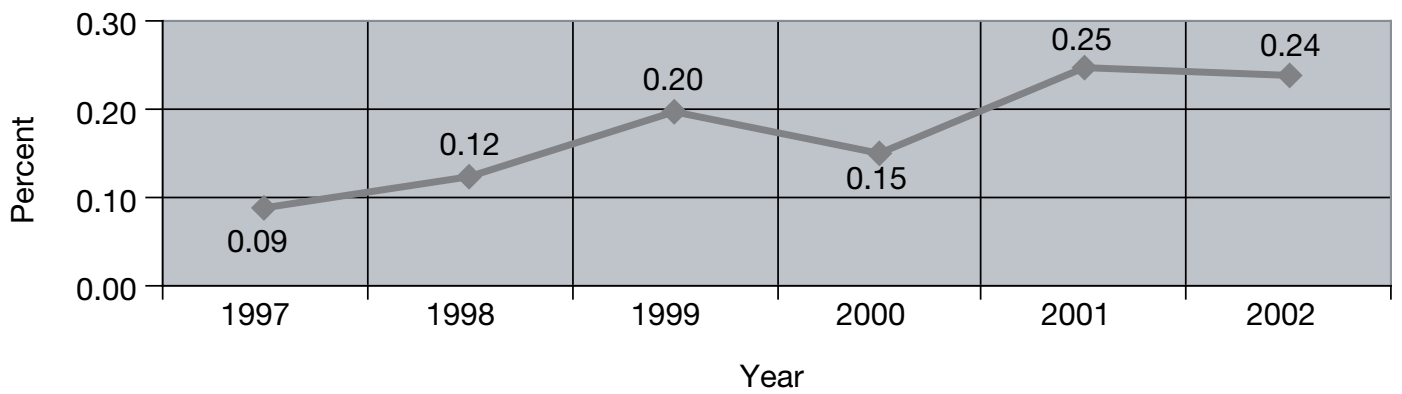

Figure 2: Proportion of small arms injuries out of total injuries from all causes

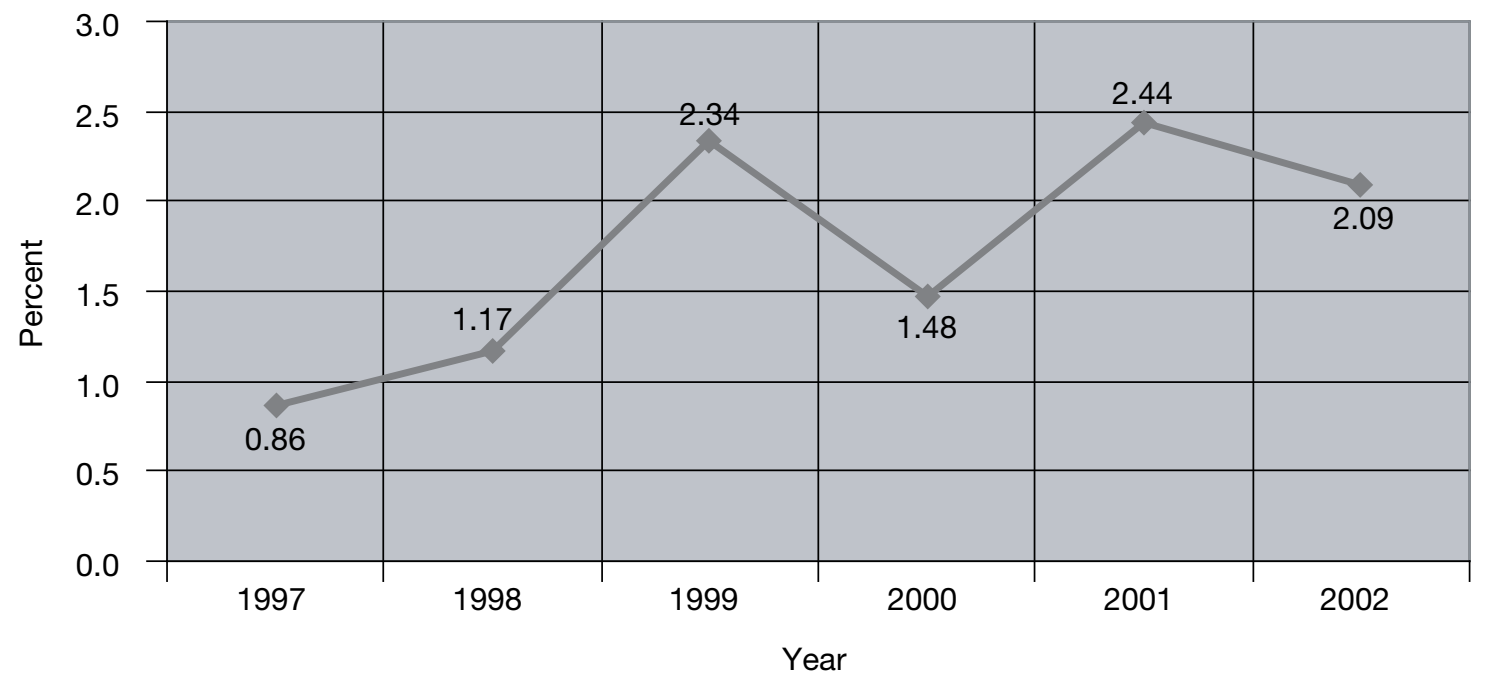

Table 2: Age distribution of the patients by sex

\begin{tabular}{lrrrrrr}
\hline & \multicolumn{1}{c}{ 0-14 yrs } & \multicolumn{1}{c}{$15-24$ yrs } & $25-34$ yrs & $35-44$ yrs & \multicolumn{1}{c}{$45+$} & Total \\
\hline Male & $13(1.9 \%)$ & $180(25.8 \%)$ & $292(41.8 \%)$ & $156(22.3 \%)$ & $57(8.2 \%)$ & $698(100 \%)$ \\
Female & $6(8.3 \%)$ & $26(36.1 \%)$ & $29(40.3 \%)$ & $9(12.5 \%)$ & $2(2.8 \%)$ & $72(100 \%)$ \\
M:F ratio & $2.2: 1$ & $6.9: 1$ & $10.0: 1$ & $17.3: 1$ & $28.5: 1$ & $9.7: 1$ \\
\hline Total & $19(2.5 \%)$ & $206(26.8 \%)$ & $321(41.7 \%)$ & $165(21.4 \%)$ & $59(7.7 \%)$ & $770^{\star}(100 \%)$ \\
\hline
\end{tabular}

* For 82 patients, age and/or sex data were not available in the records. 
incidents of intentional self-harm were only two $(0.3 \%)$. From the records, it was not possible to determine the intent of the injuries in $120(14.1 \%)$ of the cases. Case notes indicated that $42(5.0 \%)$ patients died in hospital, $800(94.5 \%)$ were discharged to go home and $5(0.6 \%)$ were still in hospital or transferred to another hospital. The outcome in the remainder was unknown or unclear from the records. Table 3 presents the outcome of injury by category of intent.

Burden on hospital facilities: Four hundred and nine $(48 \%)$ patients stayed in the wards for a duration of at least one week, $173(20.3 \%)$ stayed between 8 and 14 days, $69(8.1 \%)$ stayed between 15 and 21 days while 144 (16.9\%) stayed for more than 28 days. Duration of ward stay was missing for 11 of the patients. Duration of stay in ICU was much shorter with $11(57.9 \%)$ of the 19 patients staying between 1 and 3 days.

The 19 patients who were admitted to the Intensive Care Unit (ICU) had a cumulative total of 144 patient-days, with a median of three days per patient. In the period under review, 841 patients were admitted in the wards for a total of 15,392 days with a median of eight days per patient (Table 4). The 841 patients included all the 19 who had been admitted to ICU.

Three hundred and eleven $(36.5 \%)$ patients were given intravenous infusions/fluids with a median of 5 units per patient. The cumulative total of intravenous fluid units used by the patients was 3346 units (Table 4). One hundred and seventy five $(20.5 \%)$ of the patients were given blood transfusion with a median of two units per patient. The cumulative total of blood units given to the 311 patients was 518 .

In addition, 769 (90.3\%) of the patients required plain radiographs while 131 (15.4\%) required additional modes of imaging, including ultrasound scans, CT scans and/or contrast radiographs.

Surgery was required for $784(92.0 \%)$ of the patients. The types of surgery carried out are shown in Table 5.

Table 3: Outcome of injuries by intent

\begin{tabular}{|c|c|c|c|c|}
\hline \multirow[t]{2}{*}{ Intent } & \multicolumn{3}{|c|}{ Outcome } & \multirow[t]{2}{*}{ Total } \\
\hline & Died & Discharged & $\begin{array}{l}\text { Still in hospital/ } \\
\text { Transferred }\end{array}$ & \\
\hline Assault & $31(5.0 \%)$ & $592(94.6 \%)$ & $3(0.5 \%)$ & $626(100 \%)$ \\
\hline Unintentional & $1(1.0 \%)$ & 98 (98.0\%) & $1(1.0 \%)-$ & $100(100 \%)$ \\
\hline Intentional self harm & $1(50.0 \%)$ & $1(50.0 \%)$ & $0-$ & $2(100 \%)$ \\
\hline Total & $33(4.5 \%)$ & $691(94.9 \%)$ & $4(0.5 \%)$ & $728^{\star}(100 \%)$ \\
\hline
\end{tabular}

*For 124 patients, data on final outcome and/or intent could not be established from the records

Table 4: Burden on hospital facilities

\begin{tabular}{lcccc}
\hline & IV fluids (units) & Blood (units) & Ward days & ICU days \\
\hline Number of patients & 311 & 175 & 841 & 19 \\
Median units/days & 5 & 2 & 8 & 3 \\
\hline Total units/days & 3346 & 518 & 15,392 & 144 \\
\hline
\end{tabular}


Table 5: Types of surgeries performed $(n=842)^{*}$

\begin{tabular}{lcc}
\hline & Number & Percent \\
\hline Surgical toilet/wound excision/debridement & 618 & 73.4 \\
Laparotomy & 117 & 13.9 \\
Thoracotomy & 70 & 8.3 \\
Craniotomy/Burr holes & 27 & 3.2 \\
Skin grafts & 16 & 1.9 \\
Amputation & 5 & 0.6 \\
Other & 255 & 30.3 \\
\hline Total Surgical Procedures & 1108 & \\
\hline
\end{tabular}

*Data for 10 of the patients were not available or clear from the records

\section{Discussion}

This study represents an epidemiologic attempt to systematically describe the burden of injuries emanating from the use and abuse of small arms and light weapons on the health care system in Kenya. During the six years reviewed, 852 cases of victims of injuries from small arms and light weapons were reported. The general trend was for a rising burden. The peak age of the victims was 25-34 years and males outnumbered females in all the age groups. One out of every twenty of the patients died and three quarters of these incidents were intentional.

The results on the increasing trend of firearm violence is similar to published reports. South Africa has the highest rate of gun related murders in the world with guns killing 25 people every day. Compared to the USA, there are over 75 times more gun-related murders for every 100,000 guns in private hands in South Africa (4). In metropolitan Cape Town, the incidence both of firearm injuries and mortality tripled between 1992 and 1996 (5). In Kwazulu Natal, stab wounds declined by $30 \%$ while use of guns increased by $80 \%$ between 1987 and 1992 (6). In the USA, national studies and reports from different states have depicted gun violence escalation, especially among urban youth. In Louisiana, firearm injury at two urban Emergency Departments (ED) rose from 3.0/1000 pediatric ED patients in 1987 to 5.9 in 1993 (7). In Philadephia, a 110\% increase in the wounding frequency in the second half of a study covering the years 1986-1995 is reported (8). The escalating trend in Nairobi has been shown to persist in a more recent study. A firearm was used in $6.7 \%$ of assault cases recorded in 2004 and in $9.5 \%$ of assault cases in 2005 (9).

The trend of escalation reported in the current study is not linear as the increase in incidence was marked by a slight decline in 2000. This trend was true both for absolute numbers and also the proportions out of the total admissions and injuries from all causes. We have no explanation for the peak incidences in 1999 and 2001. It is possible that this erratic picture reflects the dynamic outcome of gunshot injuries due to an unpredictable interplay of access to weapons, crime episodes, socioeconomic crises and law enforcement activities (10). Changes in the referral system are an unlikely explanation as $\mathrm{KNH}$ has remained the only public institution with the capacity to handle the complex injuries that may result from gun shots. Kenya's neighbours continue to have wars and rebellions and this has resulted in relative ease of access to arms. Periods of increased influx of illegal arms across porous borders into markets in Nairobi may relate to instances of heightened insecurity in the city.

Thepredominanceofmalevictims is consistent with most epidemiological studies on firearm trauma. An earlier study at a Nairobi private hospital reported a gender ratio of 10:1 (11). The study by Odhiambo et al. indicated a gender ratio of 7.5:1 (9). At the National Orthopaedic Hospital in Lagos, Nigeria, males outnumbered females by 9:1 (12). About three quarters of the 
firearm injuries in the present study were due to assaults. Males, unlike females, are more likely to be involved in situations of violent assaults including robbery, the commonest assault scenarios in Nairobi (11).

Like other trauma, firearm injuries afflict the young and economically productive sector of the community. In this study, more than $90 \%$ of those affected fell within the age range of 15 and 44 years with a peak in the third decade. This peak distribution is inconsistent with reports from some high incidence regions. In California in 1991, males aged 15-24 years accounted for $72 \%$ of hospitalizations (13). Although only $25 \%$ of the victims in the current study were in this age group, it remains a worrying statistic. In a South African study of 1,736 children and adolescent victims of firearm related incidents, 86\% were between 13 and 18 years of age (5). Sixty percent were coloured males and $21 \%$ of all victims aged 12 years and above were intoxicated - a combination that suggests involvement in crime, including gang violence. The very low prevalence of suicide attempts $(0.2 \%)$ in our study is consistent with African data $(9,14)$ and contrasts Western data. In Oklahoma in 1995 the highest rate of injury was among black males aged $15-25$ years with $23 \%$ of gunshot injuries being intentionally self inflicted (15).

Our results show a geographical distribution pattern that favours urban predominance of small arms injuries. It is estimated that there are 500,000 deaths a year resulting from firearms globally, of which 300,000 are a result of armed conflict whilst 200,000 result from homicides and suicides (16) ). The so-called "Accessibility thesis" although still controversial shows that there is a correlation between arms availability and armed violence; with an increase in arms resulting in an increased risk of intentional and non-intentional injury (16). In the USA, Douglas et al have shown that the number of firearms licenses in a US county was linked to intentional death rate from firearms (17). In South Africa, firearm mortality trends have been linked to gun ownership. Four out of five of the guns used are licenced firearms. This information has been key in informing the development of South Africa's strict new firearms control bill.

Numerous and considerable resources go into treating firearm injuries. Nineteen patients needed ICU care for a total of 144 days while 841 patients stayed in hospital for a total 3,346 days and required 518 units of compatible blood. From such a study dealing with hospital records retrospectively, true estimates of the cost of care are difficult to gauge as it should consider resources consumed, physician charges, rehabilitation, home recuperation and days off work. For KNH where most of the costs are borne by the tax payer, firearm violence represents a significant cost to public financed health care. To address the violence, efforts towards gun surveillance and controlling availability are required.

In conclusion, this study has shown that the burden of injuries emanating from small arms and light weapons is significant, mainly affecting males, at a time when they are building the social and economic foundation for their lives. The problem is mainly concentrated in the urban areas and seems to be increasing in magnitude over time.

\section{Recommendations}

1. To sensitize policy makers and policy implementers on the magnitude of this problem

2. More studies into the risk factors and salient causes should be carried out so that the process of testing interventions can begin

\section{Limitations of the Study}

1. This study does not include those victims who died from injuries from small arms and light weapons before reaching the hospital.

2. The study was limited in scope as it excluded bandit-endemic population mainly situated in the northern half of the country. 


\section{References}

1. Gonzalez-Echeverri $\mathrm{G}$. The new national health care system in Colombia needs to develop a regionalized trauma care system. $6^{\text {th }}$ World Injury Congress, Montreal Canada, Plenary Conference, 11-12.

2. Rahman F., Anderson R. and Svanstrom L. Potential of using existing injury information for injury surveillance at the local level in developing countries: experiences from Bangladesh. Public Health 2000; 114: 133-136.

3. Macharia W.N., Musiime F., Nantulya V., et al. A survey of road traffic accidents in Kenya, CEU, UON, AMREF, 1998.

4. Gun Free South Africa. $h t t p / / w w w . g c a . z a$.

5. Wigton A. Firearm-related injuries and deaths among children and adolescents in Cape Town 1992-1996. South Afr. Med. J. 1999; 89(40): 407-410.

6. Muckart D.J., Meumann C. and Botha J.B. The changing pattern of penetrating torso trauma in Kwazulu/natal - a clinical and pathological review. South Afr. Med. J. 1995; 85: 1172-1174.

7. Ary R.D., Waldrop R.D. and Harper D.E. The increasing burden of pediatric firearm injuries on the emergency department. Pediatr. Emerg. Care. 1996; 12(6): 391-393.

8. Nance M.L., Stafford P.W. and Schwab C.W. Firearm injury among urban youth during the last decade: an escalation in violence. J. Pediatr. Surg. 1997; 32(7): 949-952.

9. Odhiambo W.A., Guthua S.W., Chindia M.L. and Macigo F.G. Pattern and clinical characteristics of firearm injuries. East Afr. Med. J. 2008; 85: 107-112.
10. Arnest J.L., Mercy J.L., Gibson D.R. and Ryan G.W. National Estimates of non-fatal firearm related injuries. Beyond the tip of the iceberg. JAMA. 1995; 273: 1749-1754.

11. Saidi H.S., Faya S. and Nyakiamo J. Gunshot injuries as seen at the Aga Khan Hospital, Nairobi, Kenya. East. Afr. Med. J. 2002; 79: 188-192.

12. Yinusa W. and Ogirima M.O. Extremity gunshot injuries in civilian practice; the National Orthopaedic Hospital Igbobi experience. West Afr. J. Med. 2000; 19(4): 312-316.

13. Vasser M.J. and Kizer K.W. Hospitalizations for firearm-related injuries. A population-based study of 9562 patients. JAMA. 1996; 275(22): 1734-1739.

14. Udosen A.M., Etiuma A.U., Ugare G.A. and Bassey O.O. Gunshot injuries in Calabar, Nigeria: An indicator of increasing societal violence and police brutality. Afr. Health Sci. 2006; 6: 170-172.

15. Injury update: The epidemiology of gunshot injuries In Oklahoma, 1995: A report to Oklahoma injury surveillance participants. Pg 1-5.

16. Small Arms Survey 2001: Profiling the problem. A project of the Graduate Institute of International Studies, Geneva. Oxford University Press.

17. Douglas W., Branas C., Elliot M. and Nanace M. Intentional gun deaths in the United States (abstract) $7^{\text {th }}$ World Conference on Injury Prevention and Safety Promotion. Pg 855. 